\title{
Improved Gas Chromatographic Determination of Guanidino Compounds Using Isovaleroylacetone and Ethyl Chloroformate as Derivatizing Reagents
}

\author{
Rizwan Ali ZounR, ${ }^{\dagger}$ Mumammad Yar Khuhawar, Taj Muhammad JAhangiR, and Malik AlamgiR \\ Institute of Advanced Research Studies in Chemical Sciences, University of Sindh, Jamshoro, Pakistan
}

\begin{abstract}
An improved GC method in terms of sensitivity and decrease in the analysis time has been developed for the analysis of eight guanidino compounds: guanidine $(\mathrm{G})$, methylguanidine $(\mathrm{MG})$, creatinine (CTN), guanidinoacetic acid (GAA), guanidinobutyric acid (GBA), guanidinopropionic acid (GPA), argenine (Arg), and guanidinosuccinic acid (GSA), using isovaleroylacetone (IVA) and ethyl chloroformate (ECF) as derivatizing reagents. The separation was obtained from column HP-5 (30 m $\times 0.32 \mathrm{~mm}$ i.d.) with film thickness of $0.25 \mu \mathrm{m}$ within $11 \mathrm{~min}$. The linear calibrations were obtained with 0.5 to $50 \mu \mathrm{g} / \mathrm{mL}$ with coefficient of determination $\left(R^{2}\right)$ within $0.9969-0.9998$. Limits of detections (LODs) were within $5-140 \mathrm{ng} / \mathrm{mL}$. The derivatization, separation and determination was repeatable $(n=6)$ with relative standard deviation (RSD) within $1.2-3.1 \%$. The guanidino compounds were determined in deproteinized serum of healthy volunteers and uremic patients within below LOD to $8.8 \mu \mathrm{g} / \mathrm{mL}$ and below LOD to $43.99 \mu \mathrm{g} / \mathrm{mL}$ with RSD within $1.4-3.6 \%$. The recovery of guanidino compounds calculated by standard addition from serum was within $96.1-98.9 \%$, with RSD $1.4-3.6 \%$.
\end{abstract}

Keywords Gas chromatography, guanidino compounds, derivatization, isovaleroylacetone, ethyl chloroformate, serum

(Received August 29, 2014; Accepted August 12, 2015; Published February 10, 2016)

\section{Introduction}

The guanidino compounds are characterized by the presence of basic guanidinium radical. They differ considerably in their metabolism, time distribution, biological properties and physiological functions. ${ }^{1}$ They are generated in vivo as the result of protein and amino acid metabolism in the mammalian kidneys. ${ }^{2}$ A number of them are labeled as uremic toxins because they have an ability to interact with reactive species. The guanidino compounds found in mammalians include creatinine $(\mathrm{CTN})$, guanidinosuccinic acid (GSA), guanidinoacetic acid (GAA), argenine (Arg), and guanidine (G). ${ }^{3}$ GSA and methylguanidine $(\mathrm{MG})$ are considered as uremic toxins and accumulate in the body fluids of uremic patients and indicate symptoms similar to uremia. ${ }^{4}$ A high concentration of GAA is reported in the plasma and urine of those with guanidine acetate methyl transferase deficiency.,5 Similarly, the levels of guanidino compounds are disturbed in the serum of patients with various metabolic disorders including hyper argininemia and cirrhosis. ${ }^{7,8}$ Therefore, the determination of guanidino compounds in serum has clinical importance.

A number of analytical procedures have been developed for the determination of guanidino compounds, but they involve small molecules and derivatization is carried out before their detection. The analytical procedures are mainly based on high performance liquid chromatography (HPLC), ${ }^{5,-16}$ gas

† To whom correspondence should be addressed.

E-mail: rizwan_zounr@yahoo.com chromatography $(\mathrm{GC})^{6,17-20}$ and capillary electrophoresis..$^{21-22}$ HPLC is more frequently used for the analysis of guanidino compounds, ${ }^{4}$ but capillary GC has high potential for the separation and analysis of volatile organic compounds with short analysis time. The guanidino compounds have been converted to volatile species by derivatization with hexaflouroacetylacetone (HFAA) and trimethylsilyltrifluoroacetamide, ${ }^{6,19}$ HFAA and trifluoroacetic anhydride, ${ }^{23}$ HFAA and pentfluorobenzyl bromide ${ }^{20}$ or HFAA and ethylchloroformate. ${ }^{18}$ HFAA reacted with guanidine compounds to form bis (trifluoromethyl) pyrimidine ${ }^{20}$ and another reagent reacted with imino or carboxylic acid group. HFAA contains bulky trifluoromethyl groups, which causes steric hinderance in the formation of a pyrimidine ring and is indicated by warming time of $2 \mathrm{~h}$ at $80^{\circ} \mathrm{C} .^{6,20}$ It was considered that if bulky trifluoromethyl groups are replaced with methyl and isobutyl groups in HFAA, the formation of a pyrimidine ring with guanidino compounds could take place at lower temperatures with shorter reaction time. The present work therefore examines the use of isovaleroylacetone (IVA) instead of HFAA as a derivatizing reagent for shorter reaction time at lower temperatures. The work also looks in to increasing the number of guanidino compounds analyzed by GC from biological fluids.

\section{Experimental}

The compounds G, MG, GAA, guanidinopropanic acid (GPA) (Sigma-Aldrich, St. Louis, MO), guanidino butyric acid (GBA) (Sigma-Aldrich, Switzerland), GSA (Sigma-Aldrich, GmbH, 
Germany), Arg and CTN (Sigma-Aldrich, St. Louis, MO) were used. IVA was prepared by Claison condensation of methyl isobutyl ketone (MIBK) with ethyl acetate ${ }^{24}$ as reported by Sparge et al. ${ }^{25}$ and Adams and Hauser. ${ }^{26}$ FT-IR and UV of IVA was compared with an authenticated sample. ${ }^{27}$ Ethylchloroformate (ECF) (Fluka, Switzerland) and methanol (RDH, Germany) were used. Guaranteed reagent grade hydrochloric acid $(37 \%)$, potassium chloride, acetic acid, sodium acetate, sodium tetraborate, boric acid, sodium bicarbonate, sodium carbonate, ammonium chloride and ammonia solutions were obtained from E. Merck, Darmstadt, Germany.

The stock solutions containing $1 \mathrm{mg} / \mathrm{mL}$ were prepared with $0.05 \mathrm{~N}$ hydrochloric acid in water. Further solutions were prepared by appropriate dilution. The derivatizing reagent IVA $(1 \% \mathrm{v} / \mathrm{v})$ was prepared in methanol. ECF was used without purification for derivatization. Buffer solutions $(0.1 \mathrm{M})$ between pH 1 - 10 were prepared from the following: potassium chloride adjusted with hydrochloric acid ( $\mathrm{pH} 1-2)$, acetic acid-sodium acetate ( $\mathrm{pH} 3-6)$, ammonium acetate $(\mathrm{pH} 7)$, boric acid-sodium tetraborate ( $\mathrm{pH} 7.5$ - 8.5), sodium bicarbonate-sodium carbonate $(\mathrm{pH} 9)$ and ammonium chloride ammonia solution $(\mathrm{pH} \mathrm{10).}$

\section{Equipment}

The $\mathrm{pH}$ measurements were made with an Orion $420 \mathrm{~A} \mathrm{pH}$ meter (Orion Research Inc., Boston, MA) with combined glass electrode and reference internal electrode. A spectrophotometric study was carried out with Perkin Elmer 35 (Perkin Elmer, Singapore) spectrophotometer with dual $1 \mathrm{~cm}$ path length quartz Cuvettes. GC-flame ionization detection (FID) studies were carried out on an Agilent Model 6890 network GC system interfaced with FID and split injector (Agilent Technologies, Sanata Clara, CA), hydrogen generator (Parker Baston, Analytical Gas System, H2-90, Parker Hannifin, Havorhill, MA), and using pure nitrogen (99.9\%) (British Oxygen Co., Karachi, Pakistan). The air for FID was supplied from a Fountain Air Compressor (Fountain Hills, AZ) connected with a molecular sieve. A computer with Chemstation software controlled the gas chromatograph. A HP-5 capillary column $(30 \mathrm{~m} \times 0.32 \mathrm{~mm}$ i.d.) with film thickness of $0.25 \mu \mathrm{m}(\mathrm{J} \& \mathrm{~W}$ Scientific GC column, Wilmington, NC) was used throughout the study.

\section{Analytical procedure}

Boric acid-sodium tetraborate buffer $\mathrm{pH} 8.5(0.5 \mathrm{~mL})$ and IVA $(1 \% \mathrm{v} / \mathrm{v}$ in methanol) $(1 \mathrm{~mL})$ were added to the solution $(0.5-1.0 \mathrm{~mL})$ containing guanidino compounds $(0.5-50$ $\mu \mathrm{g} / \mathrm{mL}$ each). The contents were warmed on water bath at $60^{\circ} \mathrm{C}$ for $40 \mathrm{~min}$ and allowed to cool at room temperature for $10 \mathrm{~min}$. To this solution was added $0.5 \mathrm{~mL}$ of solvent system (acetonitrile-water-methanol-pyridine, 42:42:8:8 v/v/v/v) and ECF $(0.5 \mathrm{~mL})$ and the contents were sonicated for $15 \mathrm{~min}$. Chloroform $(0.5 \mathrm{~mL})$ was added and the contents were mixed well. The layers were allowed to separate and an aliquot of organic layer was transferred to a screw capped sample vial. The extract $(1 \mu \mathrm{L})$ was injected on GC with DB-5 column with a temperature program of $90^{\circ} \mathrm{C}$ for $2 \mathrm{~min}$, followed by an increase in the temperature at a rate of $10^{\circ} \mathrm{C} / \mathrm{min}$ up to $220^{\circ} \mathrm{C}$. The nitrogen flow rate was $1 \mathrm{~mL} / \mathrm{min}$ with split ratio of 10:1. The injector and detector temperatures were fixed at 270 and $280^{\circ} \mathrm{C}$, respectively. The flow rates for FID were fixed as follows: nitrogen $45 \mathrm{~mL} / \mathrm{min}$, hydrogen $40 \mathrm{~mL} / \mathrm{min}$ and air $450 \mathrm{~mL} / \mathrm{min}$.

\section{Determination of guanidino compounds from serum}

The blood samples $(5 \mathrm{~mL})$ collected from healthy volunteers or uremic patients were kept at room temperature $\left(30^{\circ} \mathrm{C}\right)$ for $1 \mathrm{~h}$ and centrifuged at $3000 \mathrm{rpm}$ for $30 \mathrm{~min}$. The supernatant layer of the serum $(2.5 \mathrm{~mL})$ was separated and methanol $(5.0 \mathrm{~mL})$ was then added. The contents were mixed well and again centrifuged at $3000 \mathrm{rpm}$ for $30 \mathrm{~min}$. The supernatant layer was collected and $1.0 \mathrm{~mL}$ of the solution was transferred to a screw capped sample vial and processed as analytical procedure. The quantitation was carried out from linear regression equation $y=a x+b$ derived from the external calibration curve.

\section{Analysis of guanidino compounds from spiked serum samples}

Blood samples $(5 \mathrm{~mL})$ collected from uremic patients or healthy volunteers were processed as described above. Two portions of $1.0 \mathrm{~mL}$ were taken from each after deproteinization with methanol and to one portion was added a mixture of guanidino compounds $4 \mu \mathrm{g} / \mathrm{mL}$ each, then both the solutions were processed as analytical procedure. The quantitation was made from the external calibration curve and from the increase in the response with added standards.

The blood samples of uremic patients were collected with verbal consent from the medical ward of the Liaquat University of Medical and Health Sciences Hospital in Jamshoro and Hyderabad, Pakistan. The blood samples were collected in sterilized EDTA tubes by vein puncture. The blood samples of healthy volunteers who had not taken any medicine for at least one preceding week were collected from the students and employs of the Institute of Advanced Research Studies in Chemical Sciences, University of Sindh, Jamshoro, Pakistan. The samples were collected with verbal consent. The uremic patients and healthy volunteers were informed about the objectives of the project. The collected samples were quickly analyzed as received.

\section{Results and Discussion}

The guanidino compounds did not elute from the GC column, but eluted after derivatization with IVA and the GC response in terms of peak height/peak area increased $20-40 \%$ after the second derivatization with ECF. It was therefore the separation of guanidino compounds as derivatives of IVA and ECF that were examined for simultaneous optimization of the derivatization conditions in terms of the effect of the $\mathrm{pH}$, warming time and temperature, solvent system for derivatization and ease of solvent extraction of the derivatives.

The GC of guanidino compounds from the column HP-5 first as derivative of IVA and then as derivatives of IVA and ECF were examined. Each derivative eluted from the GC as a single peak and separated from the derivatizing reagent. An attempt was made to completely separate all the eight guanidino compounds as symmetrical peaks. Different temperature elution programs and nitrogen flow rates were examined. The initial temperature was varied from $80-100^{\circ} \mathrm{C}$ for 1 to $4 \mathrm{~min}$, followed by heating rate of 10 to $20^{\circ} \mathrm{C} / \mathrm{min}$ up to 200 to $250^{\circ} \mathrm{C}$ with nitrogen flow rate of $1-2 \mathrm{~mL} / \mathrm{min}$. The elution program with initial temperature of $90^{\circ} \mathrm{C}$ for $2 \mathrm{~min}$, followed by heating rate of $10^{\circ} \mathrm{C} / \mathrm{min}$ up to $220^{\circ} \mathrm{C}$, with the nitrogen flow rate of $1 \mathrm{~mL} / \mathrm{min}$ gave better sensitivity with complete base line separation and was selected. The resolution factor $\left(R_{\mathrm{s}}\right)$ between adjacent peaks was observed $>1.5$ (Figs. 1a and $1 \mathrm{~b}$ ). The order of the elution of the compounds was (1) derivatizing reagents (2) G, (3) MG, (4) CR, (5) GAA, (6) GPA, (7) GBA, (8) AR, and (9) GSA. 


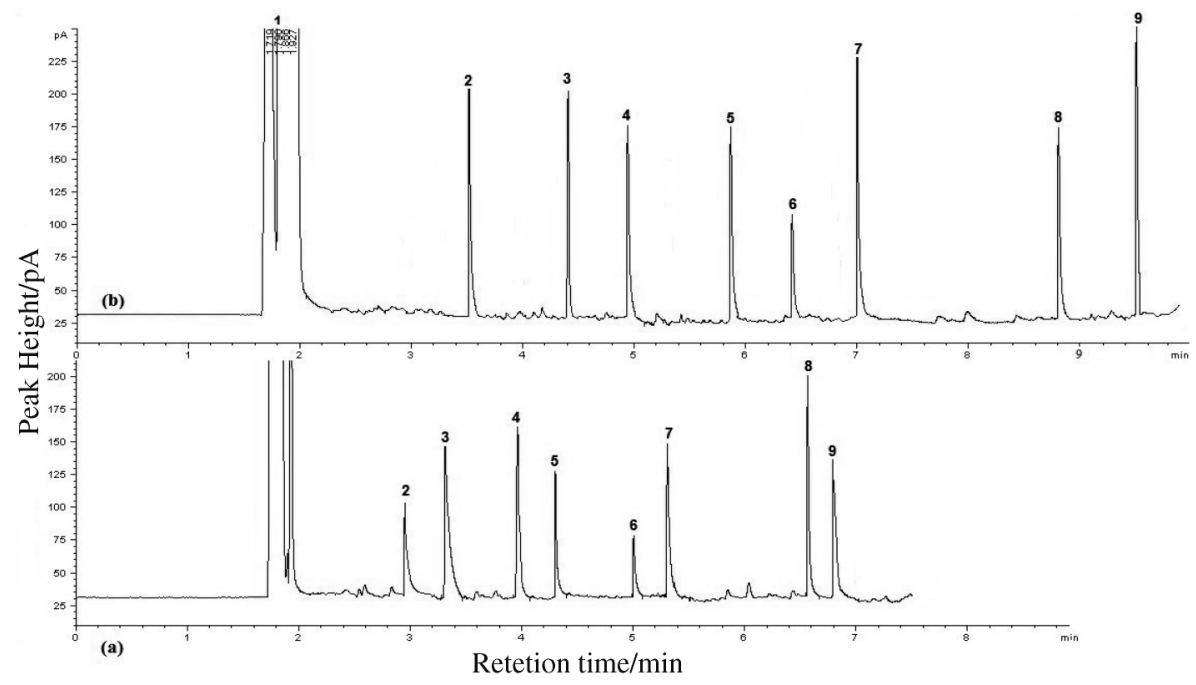

Fig. 1 GC elution and separation of guanidino compounds after using (a) IVA, (b) IVA and ECF as derivatizing reagents. Peak identifications of (1) Derivatizing reagents, (2) G, (3) MG, (4) CRT, (5) GAA, (6) GPA, (7) GBA (8) Arg (9) GSA from column HP-5 (30 $\mathrm{m} \times 0.32 \mathrm{~mm}$ i.d.) with film thickness of $0.25 \mu \mathrm{m}$ at an initial column temperature of $90^{\circ} \mathrm{C}$ for $2 \mathrm{~min}$, followed by heating rate of $10^{\circ} \mathrm{C} / \mathrm{min}$ up to $220^{\circ} \mathrm{C}$ with nitrogen flow rate of $1 \mathrm{~mL} / \mathrm{min}$. The split ratio was $10: 1$.

Table 1 Quantitative data of guanidino compounds by GC using isovaleroylacetone and ethyl chloroformate as derivatizing reagents

\begin{tabular}{lcccccc}
\hline Compound & $\begin{array}{c}\text { Calibration } \\
\text { range/ } \mu \mathrm{g} \mathrm{mL} \mathrm{mL}^{-1}\end{array}$ & $\begin{array}{c}\mathrm{LOD} / \\
\mu \mathrm{g} \mathrm{mL}^{-1}\end{array}$ & $\begin{array}{c}\mathrm{LOQ} / \\
\mu \mathrm{g} \mathrm{mL}\end{array}$ & $\begin{array}{c}\text { Retention } \\
\text { time/min }\end{array}$ & $\begin{array}{c}\text { Coefficient of } \\
\text { determination }\left(r^{2}\right)\end{array}$ & $\begin{array}{c}\text { Regression } \\
\text { equation }(n=4)\end{array}$ \\
\hline G & $0.5-50$ & 0.012 & 0.036 & 3.5 & 0.9994 & $y=8.8659 x+0.4777$ \\
MG & $0.5-50$ & 0.02 & 0.06 & 4.42 & 0.9991 & $y=10.016 x+1.0495$ \\
CTN & $0.5-50$ & 0.005 & 0.015 & 4.90 & 0.9997 & $y=22.077 x+0.432$ \\
GAA & $0.5-50$ & 0.03 & 0.09 & 5.85 & 0.9989 & $y=9.9839 x+1.0186$ \\
GPA & $0.5-50$ & 0.009 & 0.027 & 6.49 & 0.9969 & $y=12.153 x+1.9949$ \\
GBA & $0.5-50$ & 0.14 & 0.42 & 7.00 & 0.9994 & $y=10.827 x+0.7486$ \\
Arg & $0.5-50$ & 0.005 & 0.015 & 8.82 & 0.9997 & $y=14.913 x+0.7623$ \\
GSA & $0.5-50$ & 0.015 & 0.045 & 10.5 & 0.9998 & $y=13.902 x+0.0636$ \\
\hline
\end{tabular}

Abbreviations are described in the text.

Repeatability of the separation was examined in terms of retention time $(n=5)$ and relative standard deviations were observed within $2.8 \%$. GC separation obtained using IVA was used to optimize the effect of $\mathrm{pH}$, warming time and temperature and addition of derivatizing reagent per analysis. The $\mathrm{pH}$ was varied between $1-10$ at an interval of 0.5 unit and maximum response (average peak height/peak area $(n=4)$ ) was observed at $\mathrm{pH} 8.5$ using boric acid-sodium tetraborate buffer; as such these parameters were used. The warming temperature was varied from $30-90^{\circ} \mathrm{C}$ at the interval of $10^{\circ} \mathrm{C}$ and maximum response was obtained at $60^{\circ} \mathrm{C}$, so this was the temperature used for further studies. Warming time was varied from 30 - $140 \mathrm{~min}$ at an interval of $10 \mathrm{~min}$ and maximum response was recorded at $40 \mathrm{~min}$ so warming time was set at $40 \mathrm{~min}$. Now comparing the warming time and temperature with commonly used HFAA as derivatizing reagent, which requires warming time of $2 \mathrm{~h}$ at $80^{\circ} \mathrm{C}^{6,20}$ a decrease in warming time and temperature in the present method has resulted due to a decrease in steric hindrance in the formation of the pyrimidine ring. The addition of the derivatizing reagent IVA ( $1 \%$ in methanol) was varied from $0.5-2.0 \mathrm{~mL}$ at an interval of $0.5 \mathrm{~mL}$. The addition of derivatizing reagent was not critical as long as an excess of the reagent was available in the reaction mixture. However, to complete the reaction in a shorter time, the addition of $1.0 \mathrm{~mL}$ was selected.

In order to optimize the reaction conditions with the second derivatizing reagent ECF, the GC separation obtained using both derivatizing reagents IVA and ECF was used. The effect of $\mathrm{pH}$ was examined within $6-10$ and maximum response was again obtained at $\mathrm{pH} 8.5$ and 9.0. For the ease of not adding buffer a second time, $\mathrm{pH} 8.5$ was selected. The variation in the sonication of the reaction mixture at room temperature $\left(30^{\circ} \mathrm{C}\right)$ was examined for 5-20 $\mathrm{min}$ at an interval of $5 \mathrm{~min}$ and the maximum response was obtained at $15 \mathrm{~min}$ and longer, and was used. The solvent system is reported to have an influence on derivatization with $\mathrm{ECF}^{28}$ therefore the addition of methanol, acetonitrile and the solvent system (acetonitrile-water-methanolpyridine $42: 42: 8: 8 \mathrm{v} / \mathrm{v} / \mathrm{v} / \mathrm{v}$ ) to the reaction mixture was checked after the first derivatization with IVA. The addition of (acetonitrile-water-methanol-pyridine 42:42:8:8) solvent was selected as reported for similar reactions. ${ }^{28}$ The effect of order of addition of solvent and ECF for second derivatization was examined, but no significant effect was observed. Chloroform, tertiary butanol and ethyl acetate were examined as solvents for the extraction of the derivatives but chloroform indicated better extraction as reported by other researchers. ${ }^{28}$ 
Table 2 Concentration $(\mu \mathrm{g} / \mathrm{mL})$ of guanidino compounds in serum

\begin{tabular}{|c|c|c|c|c|c|c|c|c|c|}
\hline Serum No. & Age/Sex & $\mathrm{G}$ & MG & CTN & GAA & GPA & GBA & Arg & GSA \\
\hline 1 & $22 \mathrm{M}$ & $0.19(3.0)$ & $0.13(2.6)$ & 8.49 (1.8) & $0.12(2.7)$ & $0.08(3.0)$ & 0.015 (1.6) & $4.99(2.3)$ & $0.046(2.9)$ \\
\hline 2 & $19 \mathrm{M}$ & $0.21(2.8)$ & $0.12(2.4)$ & $7.99(2.3)$ & $0.16(3.0)$ & 0.07 (2.9) & $0.016(2.2)$ & $4.82(1.4)$ & $0.049(3.2)$ \\
\hline 3 & $25 \mathrm{M}$ & $0.2(1.7)$ & $0.12(1.8)$ & $8.88(1.9)$ & $0.23(1.3)$ & $0.07(2.5)$ & $0.014(2.4)$ & $5.11(2.4)$ & $0.045(3.4)$ \\
\hline 4 & $23 \mathrm{M}$ & $0.21(1.4)$ & $0.13(2.0)$ & 7.87 (1.8) & $0.21(1.6)$ & $0.09(2.0)$ & $0.014(2.9)$ & $4.67(1.8)$ & $0.051(2.3)$ \\
\hline 5 & $21 \mathrm{M}$ & $0.2(2.8)$ & $0.12(3.2)$ & $7.58(2.4)$ & $0.19(1.8)$ & - & $0.016(2.7)$ & $5.0(3.1)$ & $0.048(2.6)$ \\
\hline 6 & $19 \mathrm{~F}$ & $0.19(2.8)$ & $0.14(3.0)$ & $7.45(3.1)$ & $0.41(1.6)$ & - & $0.015(2.0)$ & $4.81(2.7)$ & 0.053 (1.9) \\
\hline 7 & $26 \mathrm{M}$ & $0.22(3.1)$ & $0.14(2.2)$ & $8.78(3.0)$ & $0.33(2.7)$ & $0.07(2.2)$ & 0.015 (1.9) & $5.99(2.1)$ & $0.051(2.0)$ \\
\hline 8 & $22 \mathrm{M}$ & $0.19(2.5)$ & $0.21(3.1)$ & $7.77(2.2)$ & $0.19(3.1)$ & - & $0.12(2.3)$ & $4.87(2.0)$ & $0.053(3.3)$ \\
\hline 9 & $23 \mathrm{M}$ & - & $0.16(1.6)$ & 7.64 (1.9) & $0.15(2.5)$ & - & $0.016(2.0)$ & 4.79 (1.9) & $0.046(1.8)$ \\
\hline 10 & $26 \mathrm{M}$ & $0.22(2.9)$ & $0.14(2.5)$ & $8.56(2.3)$ & $0.16(1.8)$ & 0.09 (1.7) & $0.017(1.7)$ & $5.12(3.1)$ & $0.0465(3.0)$ \\
\hline $10 *$ & & $0.19(2.8)$ & $0.137(3.0)$ & $8.4(2.4)$ & $0.15(1.5)$ & $0.08(2.4)$ & $0.016(2.1)$ & $4.99(3.0)$ & $0.043(2.1)$ \\
\hline 11 & $48 \mathrm{M}$ & $0.26(2.7)$ & $0.24(2.3)$ & 41.89 (1.9) & $0.19(2.0)$ & $0.12(3.6)$ & 0.09 (1.6) & $12.89(3.3)$ & $1.25(1.4)$ \\
\hline 12 & $51 \mathrm{~F}$ & $0.42(2.3)$ & $0.22(2.1)$ & $43.33(2.8)$ & $0.21(2.5)$ & - & 0.095 (1.7) & 14.65 (1.9) & $1.22(1.7)$ \\
\hline 13 & $55 \mathrm{M}$ & $0.37(2.0)$ & $0.28(1.9)$ & $43.99(2.5)$ & $0.22(1.8)$ & $0.14(3.1)$ & $0.089(2.4)$ & $15.11(3.1)$ & $0.99(1.7)$ \\
\hline 14 & $40 \mathrm{M}$ & $0.44(2.3)$ & $0.14(2.3)$ & $41.65(1.8)$ & $0.2(1.6)$ & - & 0.023 (1.9) & $13.21(2.2)$ & $0.89(1.5)$ \\
\hline 15 & $46 \mathrm{~F}$ & $0.46(1.5)$ & $0.18(3.4)$ & $41.0(3.1)$ & $0.18(2.0)$ & $0.13(2.2)$ & $0.089(2.2)$ & $13.0(2.5)$ & $1.24(1.5)$ \\
\hline 16 & $38 \mathrm{M}$ & 0.39 (1.4) & $0.18(2.4)$ & $41.0(1.8)$ & $0.18(2.7)$ & - & $0.099(3.1)$ & 12.87 (1.9) & $1.24(1.8)$ \\
\hline 17 & $28 \mathrm{M}$ & 0.28 (1.7) & $0.27(2.0)$ & $40.84(2.1)$ & $0.21(2.6)$ & $0.14(3.0)$ & $0.26(2.4)$ & $12.54(3.1)$ & $1.26(1.6)$ \\
\hline 18 & $32 \mathrm{~F}$ & $0.45(3.2)$ & $0.21(1.8)$ & $40.22(1.7)$ & $0.22(2.7)$ & $0.14(2.9)$ & $0.24(3.2)$ & $12.55(1.8)$ & $0.98(2.2)$ \\
\hline 19 & $41 \mathrm{M}$ & $0.41(1.9)$ & $0.22(2.5)$ & 41.37 (1.9) & $0.2(2.3)$ & $0.16(1.7)$ & $0.26(3.2)$ & $13.51(2.7)$ & $0.99(2.9)$ \\
\hline 20 & $60 \mathrm{M}$ & $0.55(2.1)$ & $0.26(3.2)$ & $43.99(2.1)$ & $0.22(1.9)$ & $0.34(2.9)$ & $0.026(2.0)$ & $15.55(1.8)$ & $0.89(2.2)$ \\
\hline $20 * *$ & & $0.53(1.4)$ & $0.25(1.9)$ & $43.55(1.8)$ & $0.217(1.4)$ & $0.33(2.2)$ & $0.025(2.8)$ & $15.24(1.9)$ & $0.87(1.8)$ \\
\hline
\end{tabular}

Healthy volunteers (1 to 10 ) and uremic patients (11 to 20 ). *Spiked sample; \%RSD, 1.3 - 3.4. **Spiked sample; \%RSD, $1.4-3.6$.

Repeatability for derivatization, solvent extraction and GC separation was examined $(n=5)$ in terms of retention time and peak height/peak area and RSDs were observed within $1.3-2.7 \%$.

\section{Quantitation}

Linear calibration curves were recorded by plotting average peak height/peak area $(n=4)$ against concentration within $0.5-50 \mu \mathrm{g} / \mathrm{mL}$ with coefficient of determination $\left(R^{2}\right)$ within $0.9969-0.9998$ with 19 calibrators at selected operating conditions. The limits of detection (LODs) and limits of quantitation (LOQs) calculated as signal to noise $(S / N)$ ratio 3:1 and $10: 1$ were within $0.01-0.15 \mu \mathrm{g} / \mathrm{mL}$ and $0.03-0.45 \mu \mathrm{g} / \mathrm{mL}$ respectively (Table 1). An improvement in LOD and LOQ was observed by the use of IVA instead of $\mathrm{HFAA}^{18}$ due to the increase in the sensitivity in GC-FID response owing to the increase in carbon number in IVA. The reproducibility of quantitation measured in terms of peak height and retention time was examined at inter $(n=5)$ and intra $(n=5)$ days for all the eight guanidino compounds at a concentration of $10 \mu \mathrm{g} / \mathrm{mL}$. The changes in peak height inter and intra day were observed with RSDs within 2.1 and $2.9 \%$, respectively. The corresponding RSDs for retention times were 1.8 and $2.5 \%$, respectively. The analysis of test mixtures $(n=5)$ of guanidino compounds within calibration range was conducted with relative error within $\pm 3.2 \%$.

The interfering effect of pharmaceutical additives and amino acids were examined on the determination of the guanidino compounds. The compounds glucose, galactose, starch, lactose, fructose, glycine, serine, alanine, ascorbic acid, and gum acacia were added twice to the concentration of guanidino compounds and their effect on separation, retention time and peak height were examined. The average responses $(n=4)$ were compared to the standard solution of guanidino compounds. Their presence did not affect the determination with relative error within $\pm 3.0 \%$.

\section{Sample analysis}

The method was applied for the analysis of guanidino compounds from the serum of healthy volunteers and uremic patients. Pre-deproteinized serum was examined for the contents of G, MG, CTN, GAA, GPA, GBA, Arg and GSA. A blank was also prepared from serum without addition of derivatizing reagents, but the elution of the guanidino compounds was not indicated. The identification of each analyte was based on the comparison of retention times with that of standards and by spiking of each compound in sequence. The amounts of guanidino compounds from the serum of 10 healthy volunteers ranging in age from 19 to 26 years were as follows: $\mathrm{G}$, below the limit of detection (BLOD) $-0.22 \mu \mathrm{g} / \mathrm{mL} ; \mathrm{MG}, 0.12$ $0.16 \mu \mathrm{g} / \mathrm{mL}$; CTN, $7.45-8.88 \mu \mathrm{g} / \mathrm{mL}$; GAA, $0.12-0.41 \mu \mathrm{g} / \mathrm{mL}$; GPA, BLOD - $0.09 \mu \mathrm{g} / \mathrm{mL} ;$ GBA, $0.014-0.12 \mu \mathrm{g} / \mathrm{mL}$; Arg, $4.67-5.99 \mu \mathrm{g} / \mathrm{mL}$ and GSA, $0.043-0.053 \mu \mathrm{g} / \mathrm{mL}$ with RSDs within $1.3-3.4 \%$. Similarly, the analysis of the serum of 10 uremic patients in the age range of 28-60 years indicated concentrations in $\mu \mathrm{g} / \mathrm{mL}$ as follows: $\mathrm{G}, 0.26-0.53$; $\mathrm{MG}$, $0.14-0.28$; CTN, 40.22-43.99; GAA, 0.18-0.22; GPA, BLOD - 0.34; GBA, 0.023 - 1.266; Arg, $12.54-15.55$ and GSA, $0.87-1.26$ with RSDs within $1.4-3.6 \%$ (Table 2). A sample from healthy volunteers and a sample from uremic patients were spiked with standards of all eight guanidino compounds and a corresponding increase in peak height was indicated without change in peak shape (Fig. 2a). It indicated that the deproteinized serum did not interfere with the derivatization, solvent extraction and GC separation of the guanidino compounds. The recovery from the serum of healthy volunteers and uremic patients was observed within G, 96.36-97.7\%; MG, 96.1-97.8\%; CTN, $98.1-98.9 \%$; GAA, $98.1-98.6 \%$; GPA, $97.0-97.7 \%$; GBA, $96.1-97.0 \%$; Arg, $97.4-98.0 \%$ and GSA, $97.7-98.7 \%$ with RSDs within 3\% (Fig. 2b).

The average value of 10 healthy volunteers was compared with the average value of 10 uremic patients for each guanidino compound and a $t$-test was applied at $95 \%$ confidence limits and 


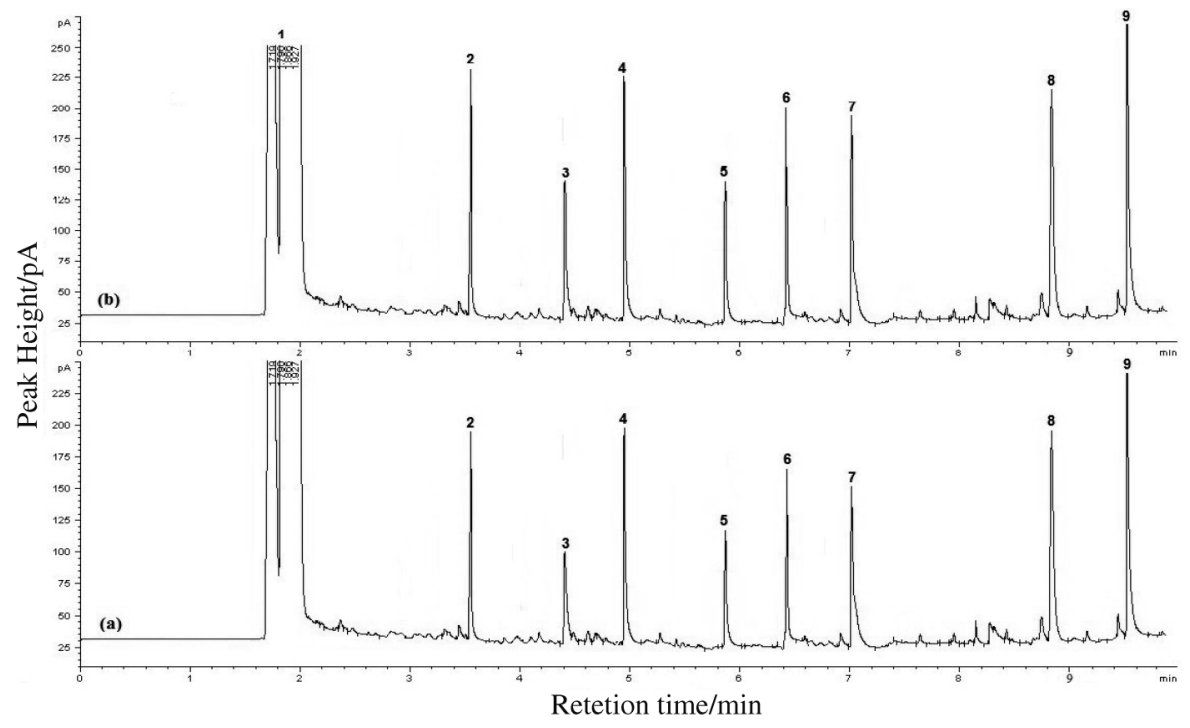

Fig. 2 (a) GC determination of guanidino compounds in serum samples of uremic patients. Peaks and conditions as in Fig. 1. (b) GC response of guanidino compounds from serum of uremic patients after spiking each compound with $4 \mu \mathrm{g} / \mathrm{mL}$. Derivatization was with IVA and ECF peak positions and conditions as in Fig. 1.

Table 3 Comparison of present method with reported methods

\begin{tabular}{|c|c|c|c|c|c|c|c|c|}
\hline $\begin{array}{l}\text { Serum } \\
\text { No. }\end{array}$ & Technique & Derivatizing reagent & $\begin{array}{c}\text { Compound } \\
\text { analyzed }\end{array}$ & $\begin{array}{l}\text { Calibration } \\
\text { range }\end{array}$ & LOD & Optimal reaction time & Applications & Ref. \\
\hline 1 & GC-MS & $\begin{array}{l}\text { Hexafluroacetylacetone and } \\
\text { monotrimethylsilyltrifluoro- } \\
\text { acetamide }\end{array}$ & 3 & $\begin{array}{c}38-7325 \\
\mu \mathrm{mol} / \mathrm{L}\end{array}$ & $\begin{array}{c}1.22-1.54 \\
\mu \mathrm{mol} / \mathrm{L}\end{array}$ & $\begin{array}{l}2 \mathrm{~h} \text { (derivatization time), } \\
\text { separation time } 5 \mathrm{~min} \\
\text { for GAA and CTN }\end{array}$ & Human urine & 6 \\
\hline 2 & $\begin{array}{l}\text { HPLC } \\
\text { gradient } \\
\text { elution }\end{array}$ & Anison & 8 & $\begin{array}{l}0.45-1310.8 \\
\mathrm{nmol} / \mathrm{mL}\end{array}$ & $\begin{array}{l}2-155 \\
\mathrm{fM}\end{array}$ & $\begin{array}{l}5 \text { min (derivatization } \\
\text { time), separation time } \\
40 \mathrm{~min}\end{array}$ & $\begin{array}{l}\text { Pharmaceuticals } \\
\text { and human } \\
\text { urine }\end{array}$ & 13 \\
\hline 3 & GC-MS & $\begin{array}{l}\text { Hexafluroacetylacetone and } \\
\text { pentafluorobenzyl bromide }\end{array}$ & 1 & $\begin{array}{c}5-100 \\
\text { nmol }\end{array}$ & $10 \mathrm{nM} / \mathrm{L}$ & $\begin{array}{l}2.25 \mathrm{~h} \text { (derivatization } \\
\text { time), separation time } \\
6.5 \text { min for GAA }\end{array}$ & $\begin{array}{l}\text { Human urine } \\
\text { and plasma }\end{array}$ & 21 \\
\hline 4 & GC & $\begin{array}{l}\text { Isovaleroylacetone and } \\
\text { ethylchloroformate }\end{array}$ & 8 & $\begin{array}{r}0.5-50 \\
\mu \mathrm{g} / \mathrm{mL}\end{array}$ & $\begin{array}{c}5-140 \\
\mathrm{ng} / \mathrm{mL}\end{array}$ & $\begin{array}{l}40 \text { min (derivatization } \\
\text { time), separation time } \\
11 \text { min }\end{array}$ & Human serum & $\begin{array}{l}\text { Present } \\
\text { method }\end{array}$ \\
\hline
\end{tabular}

a significant difference was indicated for G, MG, CTN, GBA, GSA and Arg. The results of analysis obtained agreed with reported values for GAA from healthy volunteers ${ }^{21,29}$ and GSA, GBA and MG for both uremic patients and healthy volunteers.

The present method was also compared with representative reported analytical procedures (Table 3 ) in terms of ease of derivatization, calibration range, LODs, separation time and guanidino compounds analyzed. The present method compares favorably with reported procedures.

\section{Conclusions}

An analytical procedure has been developed for the separation and determination of eight guanidino compounds using IVA and ECF as derivatizing reagents with shorter derivatization time and temperature, as well as an improvement in GC-FID sensitivity. The method is applicable for the determination of guanidino compounds from deproteinized serum from healthy volunteers and uremic patients.

\section{References}

1. O. Levillian, B. Marescau, I. Possemiers, and P. P. De Deyn, Metab., Clin. Exp., 2008, 57, 802.

2. Y. E. C. Taes, B. Marescau, A. De Vriese, P. P. De Deyn, E. Schepers, R. Vanholder, and J. R. Delanghe, Lab. Clin. Chem. Nefrol. Dialysis Trampl., 2008, 23, 1330.

3. J. Verheist, J. Berwaerts, B. Marescau, R. Abs, H. Neels, C. Mahler, and P. P. De Deyn, Metabolism, 1997, 46, 1063.

4. T. Hanai, Y. Inamoto, and S. Inamoto, J. Chromatogr. B, 2000, 747, 123.

5. C. Carducci, M. Birarelli, P. Santagata, V. Leuzzi, C. Carducci, and I. Antonozzi, J. Chromatogr. B, 2001, 755, 343.

6. C. Valongo, M. L. Cardoso, P. Domingues, L. Almeida, N. Verhoeven, G. Salomons, C. Jakobs, and L. Vilarinho, Clin. Chim. Acta, 2004, 348, 155.

7. B. Marescau, P. P. De Deyn, I. A. Qureshi, M. E. De Broe, I. Antonozzi, S. D. Cederbaum, R. Cerone, N. Chamoles, 
R. Gatti, S.-S. Kang, M. Lambert, I. Possemiers, S. E. Synderman, and M. Yoshino, Metabolism, 1992, 41, 1021.

8. B. Marescau, P. P. De Deyn, J. Holvoer, I. Possemeirs, G. Nagels, V. Saxena, and C. Maheler, Metabolism, 1995, 44, 584.

9. M. Kai, T. Miyazaki, M. Yamaguchi, and Y. Ohkura, J. Chromatogr., 1983, 268, 417.

10. M. Kai, T. Miyazaki, M. Yamaguchi, and Y. Ohkura, J. Chromatogr., 1984, 311, 257.

11. Y. Kobayashi, H. Kubo, and T. Kinoshita, Anal. Sci., 1987, 3,363 .

12. R. Gatti and M. G. Gioia, J. Pharm. Biomed. Anal., 2006, $42,11$.

13. W. Buchberger and M. Ferdig, J. Sep. Sci., 2004, 27, 1309.

14. V. K. Boppana and G. R. Rohdes, J. Chromatogr. A, 1990, 509, 279.

15. R. Gatti and M. G. Gioia, J. Pharm. Biomed. Anal., 2008, 48,754 .

16. A. J. Kandhro and M. Y. Khuhawar, J. Liq. Chromatogr. Relat. Technol., 2010, 33, 1393.

17. S. A. Majidano and M. Y. Khuhawar, J. Chromatogr. Sci., 2012, 50, 380.

18. R. A. Zounr, M. Y. Khuhawar, and T. M. Jahangir,
Chromatographia, 2013, 76, 85.

19. D. H. Hunneman and F. Hanefeld, J. Inherited. Metab. Dis., 1997, 20, 450.

20. E. A. Struys, E. E. W. Jansen, H. J. ten Brink, N. M. Verhoeven, M. S. Vander Knap, and C. Jakobs, J. Pharm. Biomed. Anal., 1998, 18, 659.

21. A. Zinellu, M. A. Caria, C. Tavera, S. Sotgia, R. Chessa, L. Deiana, and C. Carru, Anal. Biochem., 2005, 342, 186.

22. A. J. Kandhro, M. A. Mirza, and M. Y. Khuhawar, Anal. Lett., 2010, 43, 2049.

23. H. Patel and B. D. Cohen, Clin. Chem., 1975, 21, 838.

24. L. F. Lindoy, W. E. Moody, and D. Talyor, Inorg. Chem., 1977, 16, 1962.

25. J. M. Sprague, L. J. Beckham, and H. Adkins, J. Am. Chem. Soc., 1934, 56, 2665.

26. J. T. Adams and C. R. Hauser, J. Am. Chem. Soc., 1945, 66, 1220.

27. A. J. Leghari, M. Y. Khuhawar, Z. M. Ali, and L. A. Zardari, J. Chromatogr. Sci., 2010, 48, 283.

28. P. Husek, J. Chromatogr., 1991, 522, 289.

29. T. Marescau, I. A. Qureshi, P. De Deyn, J. Letarte, R. Ryba, and A. Lowentale, Clin. Chim. Acta, 1985, 146, 21. 